\title{
Analysis of some parameters related to the hydraulic infiltration of a silty-loam soil subjected to organic and mineral fertilizer systems in Southern Italy
}

\author{
Antonietta Napolitano \\ CRA-Unità di Ricerca per le Colture Alternative al Tabacco, Scafati (SA), Italy
}

\begin{abstract}
This experiment was carried out to detect the most linear process to calculate the hydraulic conductivity, with the aim to classify the soil of experimental station of the Unit for Research in Cultivations Alternative to Tobacco (CAT), locate in South Italy (Scafati, Province of Salerno), subject to different types of manure: compost and mineral fertilizer. The field tests were made by a system measuring infiltration by double, inner and outer ring, inserted into the ground. Each ring was supplied with a constant level of water from external bottle $(3 \mathrm{~cm})$, and hydraulic conductivity is determined when the water flow rate in the inner ring is constant. Four areas, two fertilized by mineral fertilizer (areas I and III) and two amended with compost (areas II and IV) at two depths, 5 and $10 \mathrm{~cm}\left(\mathrm{H}_{1}-\mathrm{H}_{2}\right)$, were analysed. The parameters were recorded at the following dates: on 18th and 19th September 2009 , respectively, at 5 and $10 \mathrm{~cm}$ of depth (H1-H2) in area I; on $7^{\text {th }}$ and 8th October 2009 in area II; on $13^{\text {th }}$ and $14^{\text {th }}$ October 2009 in area III; on 16th and 17th October 2009 in area IV. The effect of compost, used one time only, is present in all parameters, even if with a low statistical significance $(\mathrm{P}<0.01-0.05)$. This biomass stores a better water reserve $\left[\mathrm{g}(100 \mathrm{~g})^{-1}\right)-\Delta \theta$ ] and causes a lower avidity for water (bibacity) and a better speed of percolation (Ks) of exceeding water. The organic matter decreased the variability of soil along field. The studied soil showed to be almost permeable and not having any serious problem concerning rain intensity.
\end{abstract}

Correspondence: Antonietta Napolitano, CRA, Unità di Ricerca per le Colture Alternative al Tabacco, via P. Vitiello 106, 84018 Scafati (SA), Italy.

Tel. +39.081 .8563611 - Fax: +39.081 .8506206 .

E-mail: antonietta.napolitano@entecra.it

Key words: hydraulic infiltration, water content, permeability, bibacity.

Received for publication: 27 September 2009.

Accepted for publication: 27 March 2011.

(C) Copyright A. Napolitano, 2011

Licensee PAGEPress, Italy

Italian Journal of Agronomy 2011; 6:e19

doi:10.4081/ija.2011.e19

This work is licensed under a Creative Commons Attribution NonCommercial 3.0 License (CC BY-NC 3.0).

\section{Introduction}

The hydraulic conductivity is one of the most important parameters of the cultivated soil, since it explains the type of water movement into the soil itself. The saturated flow of the water is defined as the flow present in a soil, where either the larger or the smallest pores are filled with water. The unsaturated flow of the water is defined as the flow present in a soil, where the larger pores are filled with air and the smallest with water. Total porosity (Sartori et al., 1985; Pagliai, 1987), gradient of water, temperature (Grent, 2004), manure amendments (Fares et al., 2008), past and present tillage (Leeds Harrison and Yongs, 1997; Franzluebbers, 2002; Matula, 2003) of soil have influence on this parameter. Significant correlations between macroporosity and satured hydraulic conductivity were found in some previous studies on the effect on soil qualities following the agricultural machineries traffic (Marsili et al., 1998; Servadio et al., 2001, 2005; Pagliai et al., 2003). The study of hydraulic conductivity is essential to define the intensity rain in the sprinkler irrigation, the interval time (D) of irrigation and the estimation of wetting bulb in the drip irrigation. The definition of intensity rain in the sprinkler irrigation is important to avoid run off, differentiated distribution of the water and superficial erosion of the soil (Megale, 2009; Fileccia, 2002-2009; Various Authors, 2005-2006).

Hydraulic conductivity defines the interval time of irrigation, which is the ratio between the total volume of water $(\mathrm{V})$ and the hydraulic conductivity $(\mathrm{Ks})(\mathrm{D}=\mathrm{V} / \mathrm{Ks})$. In a drip irrigation system, the estimation of wetting bulb of emitter is important to design the drip system and the wet bulb; the latter is determinant to predict the lateral and vertical movements of water and to reduce the loss of water and fertilizers due to deep percolation (Mubarak et al., 2009). The present experiment was carried out to compare the mathematical processes to calculate the hydraulic conductivity and determine the most linear one, with the aim to classify the soil of experimental station of the Unit for Research in Cultivations Alternative to Tobacco (CRA-CAT), located in South Italy (Scafati, SA), subjected to different kinds of manure: compost and mineral fertilizer. Hydraulic conductivity is determined by hydraulics experiments using the Darcy's law and it can be calculated in three different ways. The first way follows the formula of Guelf infiltrometer, where the final field saturated hydraulic conductivity value (Kfs) is considered: the formula of Darcy is taken into account, but Kfs is corrected for the same parameter of wetting area. The second way is following the Darcy formula, where the mean value of hydraulic conductivity is taken in account $[\mathrm{K}(\mathrm{Vmean})]$. The third way is the same formula where the final value of hydraulic conductivity is considered $[K(R)]$; the last two ways have been calculated without corrections for wetting area. 


\section{Materials and Methods}

\section{Soil and treatments}

The instrument used in measuring the ability of a porous medium to transmit water was a system at double ring, one inner and one outer, inserted into the soil at two depths $(5$ and $10 \mathrm{~cm})$. Each ring is supplied with a constant head of water from external bottle, hydraulic conductivity is determined when the water flow rate in the inner ring is constant (Figure 1). Water level in the rings was at $3 \mathrm{~cm}$ from surface of soil. The inner ring had a diameter of $30 \mathrm{~cm}$ while the outer ring had a $53 \mathrm{~cm}$ diameter.

A gauze and a plastic plate were put inside the inner ring to avoid flow from external bottles lifting up the soil (Nigrella, 1994). This method mimics the condition of flooding irrigation. To calculate the water flow in the inner ring from reservoir a coefficient of infiltrometer was used, calculated with the following formula: (cm of external bottle $\mathrm{x}$ diameter of external bottle)/diameter of inner ring); the value obtained was 14.4. Both rings were put $5 \mathrm{~cm}$ under surface of soil $\left(\mathrm{H}_{1}\right)$ and second observation was made at $10 \mathrm{~cm}$ under soil surface $\left(\mathrm{H}_{2}\right)$. The $\mathrm{H}_{2}$ was made on saturated soil on the same location of $\mathrm{H}_{1}$ the day after (Soilmoisture Equipment, 2008). The studied soil belongs to the Experimental Station of the Unit for Research in Cultivations Alternative to Tobacco, Agricultural Research Council (CRA-CAT) of Scafati (Salerno Province of Salerno), presenting the physical and chemical parameters indicated in Table 1. The soil is a silty-loam soil, lightly alkaline, with high content of organic matter, normally equipped in nitrogen and particularly abounding in phosphorus (Table 1). Soil is classified as vitric andosol calcaric, according with the World Reference Base (for soil resource, WBR) described by Basile and Terribile (2006), and with FA0 (1998).

Four areas, two fertilized by mineral fertilizer (areas I and III) and two amended with compost (areas II and IV) were analysed; in each area two depths $\left(\mathrm{H}_{1}=0-5 \mathrm{~cm} ; \mathrm{H}_{2}=0-10 \mathrm{~cm}\right)$ were analysed, for a total of eight treatments (Table 2).

The compost used (Progeva-Evafruit), in quantity of 20 tha, was distributed five months prior to the experiment in basal dressing on other cultivation that had been ploughed in soil: the Torzella (ancient cauliflower-Brassica-Cruciferae). The mineral fertilizer used ammonium nitrate in quantity of $100 \mathrm{~kg} / \mathrm{ha}$ has been distributed partially in basal dressing and partially in top dressing by fertirrigation.

The parameters were recorded in the following dates:

On $18^{\text {th }}$ and $19^{\text {th }}$ September 2009 , respectively, at 5 and $10 \mathrm{~cm}$ of depth $\left(\mathrm{H}_{1}-\mathrm{H}_{2}\right)$ on area I;

On $7^{\text {th }}$ and $8^{\text {th }}$ October 2009 , respectively, at 5 and $10 \mathrm{~cm}$ of depth $\left(\mathrm{H}_{1^{-}}\right.$ $\mathrm{H}_{2}$ ) on area II;

On $13^{\text {th }}$ and $14^{\text {th }}$ October 2009 , respectively, at 5 and $10 \mathrm{~cm}$ of depth $\left(\mathrm{H}_{1^{-}}\right.$

$\mathrm{H}_{2}$ ) on area III

On1 $16^{\text {th }}$ and $17+$ October 2009 , respectively, at 5 and $10 \mathrm{~cm}$ of depth $\left(\mathrm{H}_{1^{-}}\right.$ $\mathrm{H}_{2}$ ) on area IV.

The values determined were the following: i) cumulated hydraulic conductivity (Ic); ii) mean of hydraulic conductivity (V1-V2); iii) instantaneous hydraulic conductivity (Ki); iv) steady state rate of fall of water during running at 5 and $10 \mathrm{~cm}$ of depth $\left(\mathrm{R}_{1}-\mathrm{R}_{2}\right)$; v) saturated hydraulic conductivity or permeability coefficient Ks: (Kfs), [K(Vmean)], [K(R)]; vi) matric flux potential $(\phi)$; vii) Water content [g $\left.\left.(100 \mathrm{~g})^{-1}\right)-\Delta \theta\right]$; viii) rate of flow (Q): $Q(\mathrm{Kfs}), Q[K(V m e a n)]$, $\mathrm{Q}[\mathrm{K}(\mathrm{R})]$; ix) Bibacity or sorptivity (B or S).

\section{Cumulated hydraulic conductivity}

The cumulated hydraulic conductivity resulting from adding all the water volumes dropped from the external bottles was recorded in $\mathrm{mm}$.

The values of hydraulic infiltration have been interpolated with a curve, which function was expressed by the exponential equation of Kostianoff

$y=a t^{b} \quad$ (Eq.1) (Cavazza and Torri, 1997)

where

$y$ is cumulated infiltration;

$t$ is time in minutes;

$a$ and $b$ are constants.

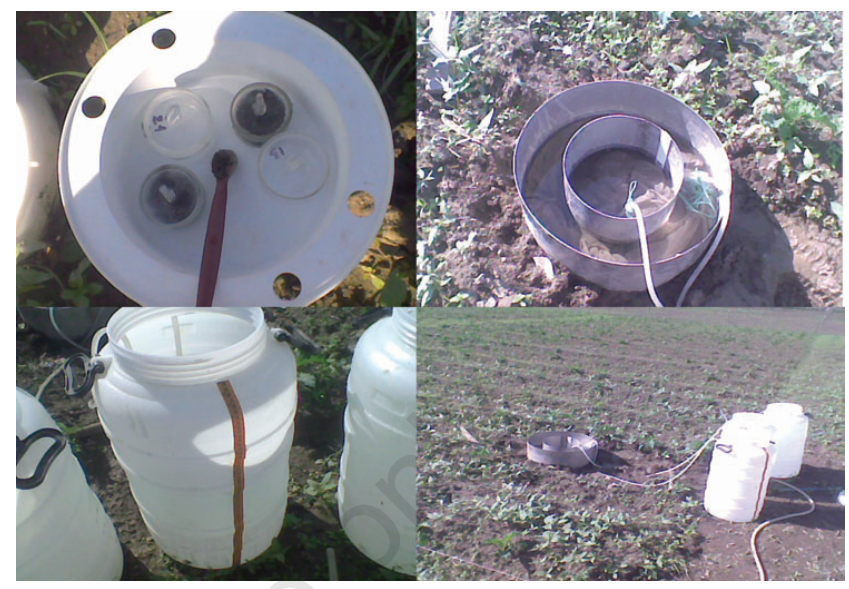

Figure 1. Double ring in field.

Table 1. Chemical and physical characteristics of the soil tested in 2005 at the CRA-CAT laboratory.

\begin{tabular}{|c|c|c|c|}
\hline Parameters & Unit & Values & Classifications \\
\hline Sand content & $g(1000)^{-1}$ & 350.5 & \\
\hline Slimy content & $g(1000)^{-1}$ & 575 & \\
\hline Clay content & $g(1000)^{-1}$ & 75 & Silty-loam soil \\
\hline Field capacity & $g(100 g)^{-1}$ & 26 & \\
\hline Wilting point & $g(100 g)^{-1}$ & 9 & \\
\hline Bulk density & $\mathrm{t} \mathrm{m}^{-3}$ & 1.33 & \\
\hline $\mathrm{pH}$ & - & 8.05 & Under alkaline \\
\hline $\mathrm{CaCO}_{3}$ total & $\mathrm{g} \mathrm{Kg}^{-1}$ & 46 & Average (SISS) \\
\hline $\mathrm{CaCO}_{3}$ active & $\mathrm{g} \mathrm{Kg}^{-1}$ & 32 & Low (SISS) \\
\hline Electrical conductivity & $d S^{-1}$ & 0.23 & Very low (SISS) \\
\hline Cation exchange capacity & Cmoli Kg-1 $^{-1}$ & 23.8 & High (SISS) \\
\hline Phosphorus & $\mathrm{mg} \mathrm{Kg}^{-1}$ & 35.5 & Very high (SISS) \\
\hline Total nitrogen (N) & $\mathrm{g} \mathrm{Kg}^{-1}$ & 1.2 & Normal (SISS) \\
\hline Organic matter $(\mathrm{C})$ & $g(100 g)^{-1}$ & 2.15 & High (SISS) \\
\hline $\mathrm{C} / \mathrm{N}$ & - & 10.5 & Normal (SISS) \\
\hline
\end{tabular}

SISS, Italian Society of Soil Science.

Table 2. Description of treatments.

\begin{tabular}{lccc} 
Treatment & Area & Depths & Type of fertilizer \\
MI- $\mathrm{H}_{1}$ & I & $\mathrm{H}_{1}$ & Mineral \\
MI- $\mathrm{H}_{2}$ & I & $\mathrm{H}_{2}$ & Mineral \\
\hline${\text { CII- } \mathrm{H}_{1}}_{\text {CII- } \mathrm{H}_{2}}$ & II & $\mathrm{H}_{1}$ & Compost \\
\hline MIII- $\mathrm{H}_{1}$ & II & $\mathrm{H}_{2}$ & Compost \\
MIII- $\mathrm{H}_{2}$ & III & $\mathrm{H}_{1}$ & Mineral \\
\hline CIV- $\mathrm{H}_{1}$ & III & $\mathrm{H}_{2}$ & Mineral \\
CIV- $\mathrm{H}_{2}$ & IV & $\mathrm{H}_{1}$ & Compost \\
\hline
\end{tabular}




\section{Mean of hydraulic conductivity}

The mean of hydraulic conductivity (V mean) was calculated as ratio between the total volume of infiltrated water in $\mathrm{mm}$, and the total time in minutes multiplied by the infiltrometer coefficient of the double ring system.

The survey was organised as follows: three measures were taken at a 5 min interval, 7 measures at a 10 min interval, and the remaining measurements each 20 min, until constant speed. The hydraulic infiltration is the speed with which the water pierces the soil and depends on the water load on the ground; this value decreases in damp ground and is minimum in the saturated ones.

This parameter is very important to regulate the intensity of sprinkler irrigation, the intervals of time for irrigation and estimation of wetting bulbs in the drop irrigation. The intensity of the rain (Ip) in sprinkler irrigation must be lower than the saturated hydraulic conductivity (ks) to avoid run off, differentiated water distribution and superficial soil erosion (Ip<Ks) (Megale, 2009).

Interval time (D) of irrigation is influenced by hydraulic speed because it is the ratio between volume of single irrigation (V) and saturated hydraulic conductivity ( $\mathrm{D}=\mathrm{V} / \mathrm{Ks}$ ). In conclusion, the saturated hydraulic conductivity measures the extent to which water moves laterally and vertically from an emitter in drip irrigation, so that the estimation of wetting bulb can be made.

\section{Instantaneous hydraulic conductivity}

The instantaneous hydraulic conductivity was measured by the first derivative of the equation of Kostianoff

where

$$
y^{\prime}=a b t^{b-1}
$$

$y^{\prime}$ is first derivative of $y$ from function of Eq. 1 .

\section{Final rate of water level change}

The final change of water level change $\left(R_{1}-R_{2}\right)$ to $5-10 \mathrm{~cm}$ of depth has been calculated as the ratio between final constant infiltration and corresponding final time interval expressed in minutes and it was multiplied by infiltrometer coefficient to correct difference existing between diameters of reservoir and inner ring.

\section{Field saturated conductivity}

The Field saturated conductivity expressed in $\mathrm{cm} \mathrm{sec}^{-1} * 10^{-4}$ has been calculated by the following equation (Soilmoisture Equipment, 2008):

$$
K f s=\frac{C A R}{\left[2 \pi H^{2}+C \pi a^{2}+\left(\frac{2 \pi H}{\alpha^{*}}\right)\right]} \text { (Eq. 3) }
$$

where

$\mathrm{A}$ is a section of cylinder in $\mathrm{cm}^{2}\left(706.2 \mathrm{~cm}^{2}\right)$;

$\mathrm{R}$ is a steady state rate of fall corresponding to $\mathrm{H}_{1}$ and $\mathrm{H}_{2}$ (deep 5 and $10 \mathrm{~cm}$ ) of water in the inner reservoir when the head of water is established. They were final speeds in $\mathrm{cm} \mathrm{sec}^{-1}\left(\mathrm{R}_{1}-\mathrm{R}_{2}\right)$;

$\mathrm{C}$ is a factor shape dependent on value $\mathrm{H} / \mathrm{a}$, calculated by the graphic of Reynolds (1993). In this work, H/a resulted to be 0.33 and 0.66 with corresponding values of $\mathrm{C}$ of 0.25 and 0.45 respectively, in the Reynolds' graph (Figure 2);

$\mathrm{H}$ is a depth of sampling, in $\mathrm{cm}\left(\mathrm{H}_{1}=5 \mathrm{~cm}, \mathrm{H}_{2}=10 \mathrm{~cm}\right)$;

$\mathrm{A}$ is a radius of the well (internal cylinder $=15 \mathrm{~cm}$ );

$\alpha^{*}$ is a related to texture of the soil, usually $0.12 \mathrm{~cm}^{-1}$ from the table of Reynold (1993) and Erlick et al. (1989) (Table 3).

$\pi$ is the constant 3.14 .

\section{Matric flux potential $(\phi)$}

The matric flux potential $(\phi)$ expressed in $\mathrm{cm}^{2} \mathrm{sec}-1 \times 10^{-3}$ is the quantity of water that, if available on the plant surface, would be removed from the ground and is calculated as follows:

$$
\phi=\frac{C A R}{\left[\left(2 \pi H^{2}+C \pi a^{2}\right) \alpha^{*}+2 \pi H\right]}
$$

\section{Water content}

The humidity is often referred as water content and is obtained drying the sample at $105{ }^{\circ} \mathrm{C}$ in an oven for $48 \mathrm{~h}$; the mass of water lost is expressed as change of percentage of the height $\left[\mathrm{g}(100 \mathrm{~g})^{-1}\right]$ and as change of volume $(\Delta \theta)$.

$\Delta \theta$ is the difference between the water content in volume of saturated soil and the water content of soil before the infiltration trial, expressed in $\mathrm{cm}^{3} / \mathrm{cm}^{3}$.

\section{Hydraulic flow in porous medium or soil permeability}

The hydraulic flow in porous medium or soil permeability has been calculated by Darcy's formula (Fileccia, 2002-2009; Various Authors, 2005-2006).

Henry Darcy in 1956 related the water flow in $\mathrm{Lh}^{-1}(\mathrm{Q})$, with the area soil sample in $\mathrm{mm}^{2}(\mathrm{~A})$, and the hydraulic gradient in $\mathrm{mm}(\mathrm{H})$. The equation reveals that hydraulic flow $(Q)$ and the piezometric head to be directly proportional variables, and flow $(\mathrm{Q})$ and length (L) of the sample to be inversely proportional variables:

$$
Q=\frac{K s A H}{L}
$$

where

$K s$ is the satured hydraulic conductivity;

$A$ is the section of cylinder in $\mathrm{cm}^{2}\left(706.2 \mathrm{~cm}^{2}\right)$;

$H$ is the sum of $\mathrm{H}^{\prime}$ and $\mathrm{L}\left(H^{\prime}=3 \mathrm{~cm}\right.$, is the water height into the cylinder, from soil surface);

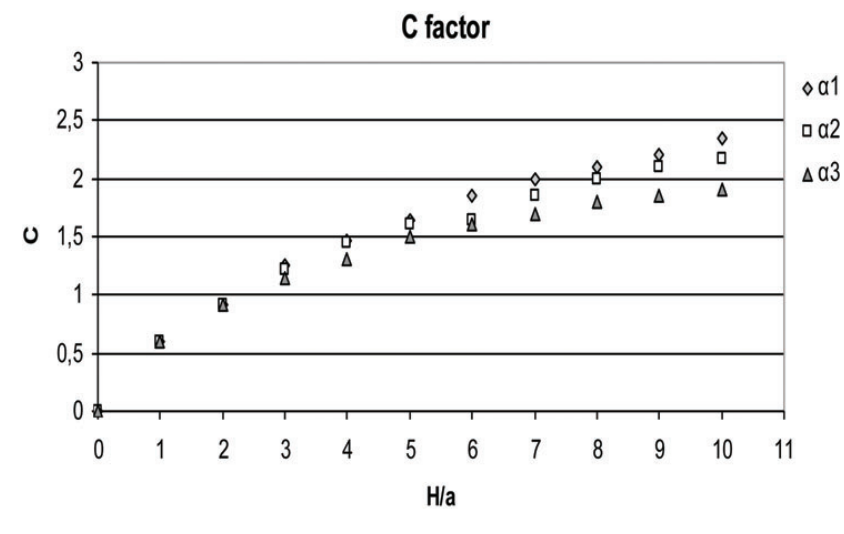

Figure 2. Reynolds' Graph.

Table 3. Table of Reynolds (1993) and Elrick et al. (1989),

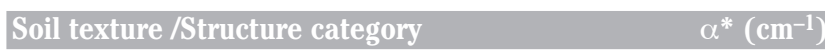

Compacted, unstructured, clayey materials such $\quad 0.01$

as landfill caps and liners, lacustrine or marine sediments, etc.

Soils both fine textured (clays) and unstructured $\quad 0.04$

Most structured soils from clays through loams; including 0.12 unstructured medium to fine sands (first choice for most soils)

Coarse and gravely sands; may include some highly structured $\quad 0.36$ soils with large cracks (vertisoils) and macropores 
$L$ is the inserting depth on soil $(3-10 \mathrm{~cm})$.

Rings are inserted into the soil at two depths (5 and $10 \mathrm{~cm})$; satured hydraulic conductivity or coefficient of permeability in constant running $\left(\mathrm{mm} \mathrm{min}^{-1}\right)$ has been calculated by soilmoisture formula Kfs, as well as with Ks (mean V) and with Ks (R). The last two were calculated by multiplying mean $V$ and final $R$ for the ratio $H / L$ (Megale, 2009), where $\mathrm{H}=\left(\mathrm{H}^{\prime}+\mathrm{L}\right) . \mathrm{H}^{\prime}$ is head of water of inner ring $(3 \mathrm{~cm}$ is the piezometric head, corresponding to the height of water on the soil surface) and $\mathrm{L}$ is the length of the porous matrix, namely the length of cylinder inserted into the ground at the two depths (Bianchi, 2003). The mathematic law on water distribution for horizontal and vertical Ks variability is logarithmic (Fileccia, 2002-2009; Various Authors, 2005-2006).

\section{Bibacity or sorptivity}

The bibacity (B) or sorptivity (S) is the ability of the soil to adsorb water at starting of the infiltration trial:

$$
S=\sqrt[2]{2 \Delta \Theta \Phi}
$$

where

$\Delta \theta$ is the variation of water content.

The statistical analysis was performed by the Post Hoc Test, data analysis software system Statistica v. 7.1 (www.statsoft.com).

\section{Results}

\section{Water content}

The calculated water content revealed a decreasing trend from area I to area IV, among the selected areas. The most evident gradient was observed in samples almost saturated, probably for the differences in texture or in porosity, maybe caused by deep tilling. The values of water content before the experiment are lower at $5 \mathrm{~cm}$ than at $10 \mathrm{~cm}$, as shown in Figure 3. The soil treated by compost showed a higher value of water content at the beginning $(31.42 ; 29.08)$ and lower at the end of the experience $(44.66 ; 49.12)$, compared with the values recorded from mineral fertilized soil (Figures 4 and 5). The variability of water content in the soil treated with compost is smaller than the one recorded for the areas with nitrogenous fertilizer, at 5 and $10 \mathrm{~cm}$ of depth, maybe due to the fact that the organic matter retains water. The variability of water content, expressed as $\Delta \theta$ of volume $\left(\mathrm{cm}^{3} / \mathrm{cm}^{3}\right)$, is lower in areas amended with compost $(0.20-0.064)$ than in those treated with mineral fertilizer (0.30-0.10) (Figure 6). The lowest water content change in soil amended with compost makes the environmental conditions more favourable for the plants. The statistical analyses showed that the change of water content in volume, the type of fertilizations (mineral and organic) and the depth are proportional dimensions (Table 4).

\section{Mean of hydraulic conductivity ( $\mathrm{V}$ mean)}

The mean of infiltration coefficients (or permeability coefficients) resulted higher in the areas amended with compost, whether analyzing separately $\mathrm{V}_{1}$ and $\mathrm{V}_{2}\left(4.33-1.51 \mathrm{~mm} \mathrm{~min}^{-1}\right.$ vs $\left.3.19-1.47\right)$ or the mean values without considering the different depths (2.92 vs 2.33) (Figures 7 and 8). The differences among the logarithmic data of mean hydraulic conductivity (V mean) are significant $(0.046 \%)$, showing higher values in areas treated with compost than in mineral fertilized areas, confirming the good porosity of the soil amended with compost (Pagliai et al., 1987). The natural differences in texture and tilling of field probably cause changes in the elaborated values between areas fertilized in the same way; however, this event is more evident in soil treated with mineral fertilizer, since compost reduces discontinuity of soil texture and porosity.

\section{Final rate of water level change}

The differences in the final values of infiltration $\left(R_{1}-R_{2}\right)$ among the theses decrease using $R$ as absolute value and become significant $(0.038 \%)$ when $R$ values are transformed in logarithmic values (Figure 9 and 10). The compost, in conclusion, reduces changes of water content and makes the soil porosity or the texture uniform; this is clearly stated in Figures 7 and 9, seeing separately mineral and compost theses. The final speed of infiltration in constant running is obtained in shorter time in organic fertilized areas than in the mineral fertilized ones from area II and IV, 193-195.00 min at $5 \mathrm{~cm}$ of depth and 205-91.00 min at $10 \mathrm{~cm}$ of depth; from area I and III, 196-205.00 min at $5 \mathrm{~cm}$ and 215-227.00 min at $10 \mathrm{~cm}$ (Table 5). The curves resulting from analyses

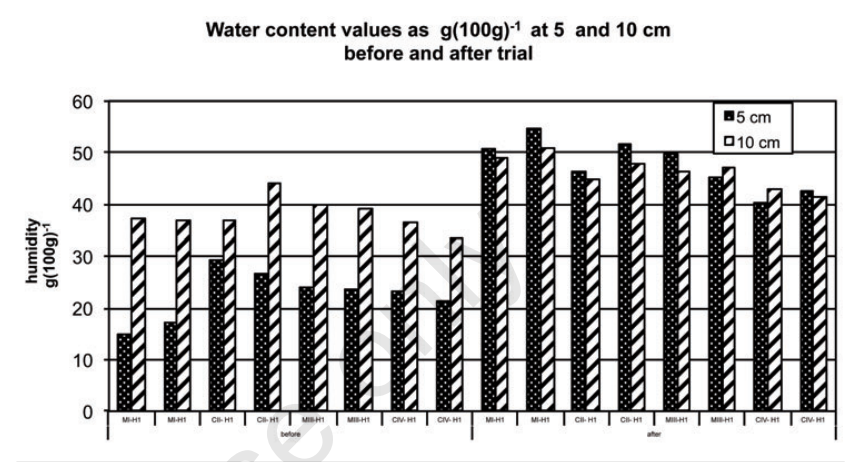

Figure 3. Values of water content.

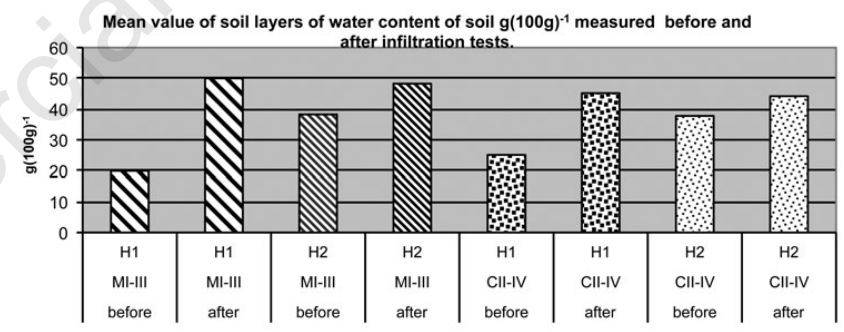

Figure 4. Water content in organic and mineral areas.

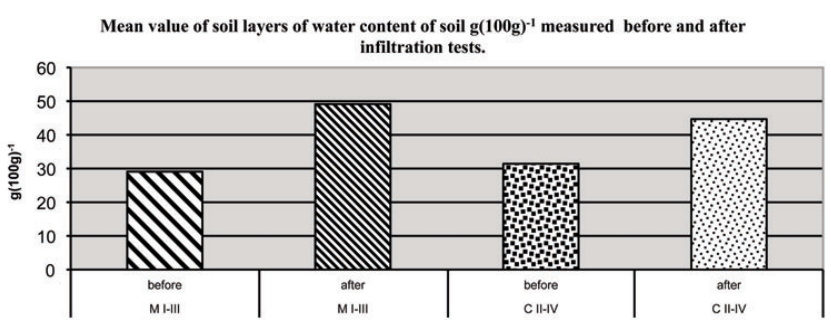

Figure 5. Mean of water content in organic and mineral areas.

Table 4. Unvaried test for change of water volume $(\Delta \theta)$.

$\begin{array}{ccccc}\text { Treatment } & \text { MII-III-H } & \text { CII-IV-H } & \text { MII-III-H } & \text { CII-IV-H } \\ & 0.30 & 0.20 & 0.10 & 0.064\end{array}$

MI-III- $\mathrm{H}_{1}$

\begin{tabular}{lccc} 
CII-IV-H & 0.000103 & & \\
\hline MI-III- $H_{2}$ & 0.000059 & 0.00103 & \\
CII-IV-H & 0.000045 & 0.000059 & 0.0002 \\
\hline
\end{tabular}


of the values of cumulated speed and instantaneous speed of water, or the equations obtained with data collected from areas I and II (treatments $\mathrm{MI}-\mathrm{H}_{1}$ and $\mathrm{CII}-\mathrm{H}_{1}$ ) are showed in Figures 11 and 12.

The soil can be classified as sandy, for the mean of hydraulic conductivity $\left(\mathrm{V}_{1}-\mathrm{V}_{2}\right.$ mean) recorded at $0-5 \mathrm{~cm}$ of depth, with mean values ranging between 19.16-25.69 $\mathrm{cm} \mathrm{h}^{-1}$ respectively, recorded from mineral and organic fertilized soils.

The soil can be classified as loamy-sand, for the water mean conductivity recorded at $10 \mathrm{~cm}$ of depth, with mean values ranging between
8.85-9.04 $\mathrm{cm} \mathrm{h}^{-1}$ or, finally, as sandy considering the mean of all recorded values (14-17.51 $\mathrm{cm} \mathrm{h} \mathrm{h}^{-1}$ ), according to table of 0 'Neal reported by Falciai (1993) (Table 6).

Comparing the recorded values of water conductibility with those elaborated from Ooserbaan and Nijland (Nigrella, 1994) (Table 7), the soil can be classified as medium sand considering the mean speeds $\left(\mathrm{V}_{1}-\mathrm{V}_{2}\right)$ of the water at 5 and $10 \mathrm{~cm}$ of depth and as at medium texturefine-sand considering the final values of $R_{1}-R_{2}$. The conductivity is middle high or high.

Table 5. Synthesis of different parameters of field in CRA-CAT 2009 (Scafati, Province of Salerno).

\begin{tabular}{|c|c|c|c|c|c|}
\hline Treatment & $\begin{array}{l}\text { Cumulated time } \\
\text { in minutes }\end{array}$ & $\begin{array}{l}\text { Velocity mean } \\
\left(\text { V1-V2) in } \mathrm{cm} \mathrm{h}^{-1}\right.\end{array}$ & $\begin{array}{l}\text { Final velocity } \\
\text { (R1-R2) } \mathrm{cmh}^{-1}\end{array}$ & $\begin{array}{l}\text { Instantaneous velocity } \\
\text { (Ki) in } \mathrm{cm} \mathrm{h}^{-1}\end{array}$ & $\begin{array}{l}\text { Cumulated velocity } \\
\text { (Ic) in mm }\end{array}$ \\
\hline MI- $\mathrm{H}_{1}$ & 196 & 24.62 & 15.1 & 10.70 & 804.24 \\
\hline CII-H & 193 & 35.48 & 11.4 & 11.713 & 1141.2 \\
\hline MIII- $\mathrm{H}_{1}$ & 205 & 13.70 & 8.6 & 4.52 & 468.00 \\
\hline CIV-H ${ }_{1}$ & 195 & 16.50 & 13.0 & 5.45 & 536.4 \\
\hline MI- $\mathrm{H}_{2}$ & 215 & 13.98 & 14.3 & 7.77 & 501.12 \\
\hline CII- $\mathrm{H}_{2}$ & 205 & 12.85 & 11.9 & 10.146 & 439.2 \\
\hline MIII- $\mathrm{H}_{2}$ & 227 & 3.71 & 2.4 & 1.99 & 140.4 \\
\hline CIV-H ${ }_{2}$ & 91 & 5.22 & 4.3 & 2.86 & 79.2 \\
\hline
\end{tabular}

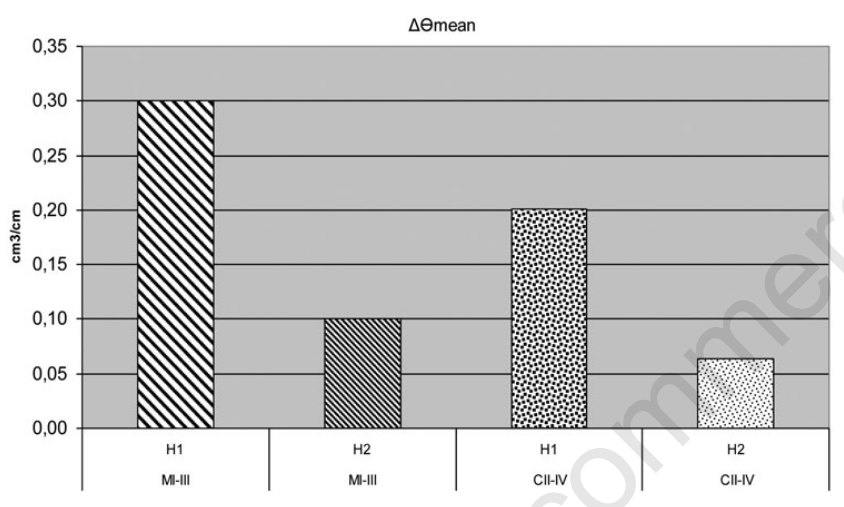

Figure 6. Variation of water content expressed as volume.

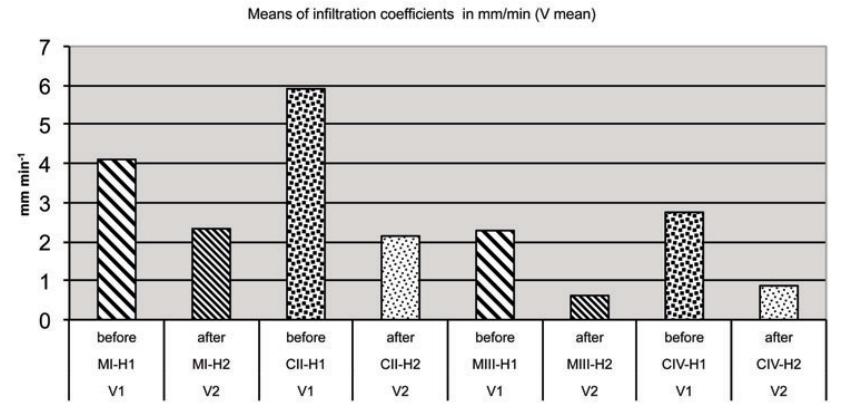

Figure 7. Mean velocity (V mean) of infiltration.

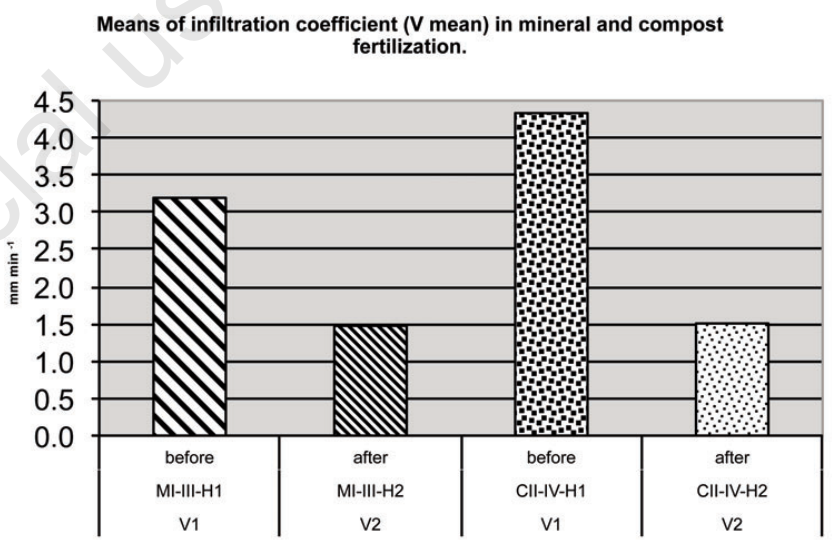

Figure 8. Mean of infiltration coefficients in two different theses.

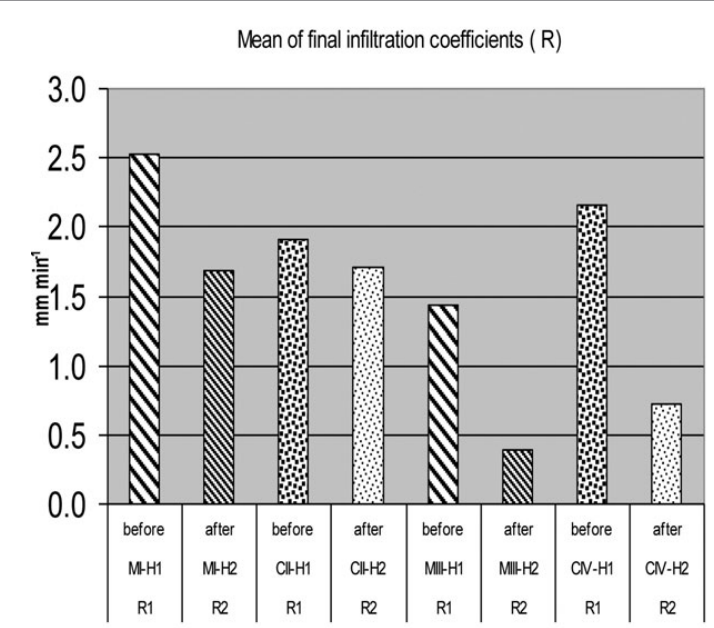

Figure 9. Final hydrology coefficients $\left(R_{1}-R_{2}\right) \mathrm{mm} \mathrm{min}^{-1}$. 
ferences are statistically significant, to $0.424 \%$, probably as effect of

\section{Field saturated conductivity}

The studied soil of Scafati, considering the values of conductivity of water at the saturation point or permeability (kfs), can be considered as very fine sand (Table 8).

The middle values of kfs are $9.81-10.05 \mathrm{~cm} \mathrm{sec}^{-1} \times 10^{-4}$ in not-saturated field and $3.83-4.65 \mathrm{~cm} \mathrm{sec}^{-1} \times 10^{-4}$ in saturated field, with a mean of $6.82-7.35 \mathrm{~cm} \mathrm{sec}^{-1} \times 10^{-4}$, respectively, recorded from areas mineral fertilized and from those amended with compost.

In Table 6 the above mentioned values are expressed as $\mathrm{m} \mathrm{sec}^{-1}$, so corresponding to unit of measure $10^{-6}$, the soil is classified as finesand. Using the unvaried test to analyze the absolute values of Kfs no significant difference was found among the theses, while the same values, changed in logarithmic values and elaborated with the final speed of infiltration, resulted significant to $0.452 \%$, due to the difference in practices of fertilization. The highest values have been recorded in the thesis organically treated (Figure 13).

\section{Matric flux potential}

The matric flux potential $(\phi)$ is the quantity of water removed from the soil for unit of area (potentially available for the plants). This parameter fellows shape similar to that of the conductivity at saturation point, in fact it is higher in organically treated areas than in the mineral fertilized ones (Figure 14). The mean values of the matric potential flux of the medium are $8.18-8.37 \mathrm{~cm}^{2} \times 10^{-3}$ in not-saturated field and 4.38-5.31 $\mathrm{cm}^{2} \times 10^{-3}$ in saturated field, respectively in mineral and in organic amended field, with a total mean of $6.56 \mathrm{~cm}^{2} \times 10^{-3}$. The dif-

Table 6. Table of different values of saturated hydraulic conductivity (Ks) $\mathrm{cm} \mathrm{h}^{-1}$ (Falciai, 1993).

\begin{tabular}{lc} 
Soil texture & $\left.\mathrm{Ks}_{(\mathrm{cmh}-1}\right)$ \\
Clay & $0.1-0.5$ \\
Loam & $0.5-2$ \\
\hline Silty (medium texture) & $2-6$ \\
Loamy-sand & $6-12$ \\
\hline Sand & $12-25$ \\
Sandy-coarse & $25-100$ \\
\hline
\end{tabular}

Table 7. Table of different values of saturated hydraulic conductivity (Ks) in different kinds of soil).

\begin{tabular}{lc} 
Soll texture & $\mathrm{Ks}\left(\mathrm{cmh}^{-1}\right)$ \\
Gravely coarse grained sand & $42-208$ \\
Average sand & $4-21$ \\
\hline Medium texture - fine sand & $4-12$ \\
Medium texture - clay at compact texture & $2-8$ \\
\hline Medium texture & $0.8-20$ \\
Medium texture - clay at loose texture & $0.008-0.8$ \\
\hline Compact clay & $<0.008$ \\
\hline
\end{tabular}

Table 8. Coefficient of permeability (reported by USACE, 1999).

\begin{tabular}{lcc} 
& Type of soil & $\mathrm{K}\left(\mathrm{m} \mathrm{sec} \mathrm{sec}^{-1}\right)$ \\
Coarse grained soils & Clean gravel & $10^{-1} \div 1$ \\
& Clean sand, sand and gravel & $10^{-5} \div 10^{-2}$ \\
Fine grained soils & Very fine sand & $10^{-6} \div 10^{-4}$ \\
& Loam & $10^{-8} \div 10^{-6}$ \\
& Homogeneous clay & $<10^{-9}$ \\
\hline
\end{tabular}

the different practices of fertilization.

\section{Hydraulic cumulated conductivity}

The infiltration cumulated parameter differs in significant way (0.034\%) (Figure 15). The mean final values at $5 \mathrm{~cm}$ for organic and mineral fertilized soil are 838.7-636.12, respectively.

\section{Bibacity (B) or sorptivity (S)}

The bibacity value is low and almost constant at 5 and at $10 \mathrm{~cm}$ of depth in the compost dunged areas (1.83-0.79 $\left.\mathrm{cm}^{*} \mathrm{sec}^{-1 / 2}\right)$ compared with that recorded in mineral fertilized areas $\left(2.22-0.92 \mathrm{~cm} \mathrm{sec}^{-1 / 2}\right)$ (Figure 16).

The sorptivity or bibacity characterized the first phases of infiltration process, depending either on the intrinsic permeability of the soil, on the ability of the soil to store water, or on the difference of pressure power between the water in surface and the water into the soil, at the starting state (Nigrella, 1994). The bibacity changed in significant way when correlated with depth and with the relation between depth and type of manure. The bibacity showed a higher decrease in areas amended with compost, overall at $5 \mathrm{~cm}$ of depth, and less at $10 \mathrm{~cm}$ in saturated areas.

Comparing data of $\mathrm{Kfs}$, $\mathrm{K}\left(\right.$ Vmedia) and $\mathrm{K}(\mathrm{R})$ in $\mathrm{mm} \mathrm{h}^{-1}$ with data

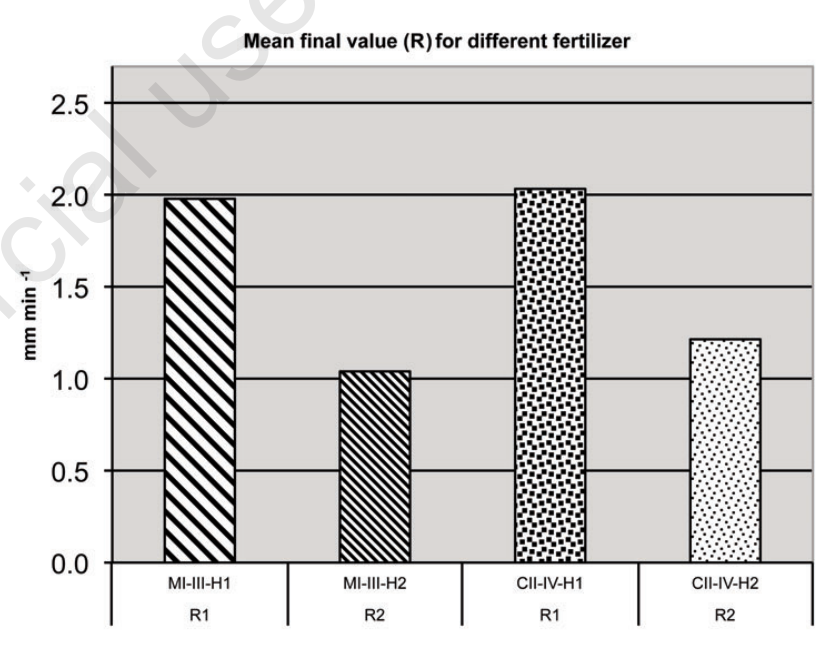

Figure 10. Mean final coefficients (R).

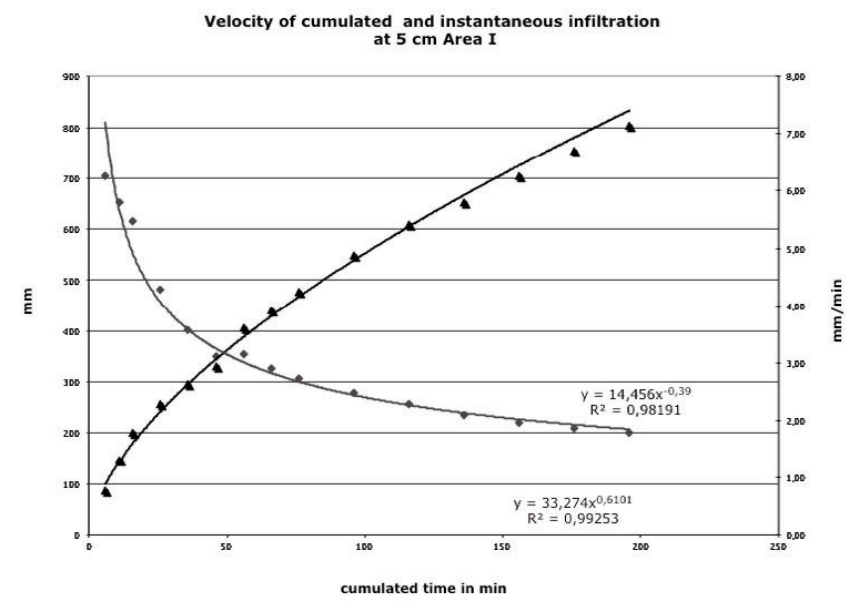

Figure 11. Cumulated and instantaneous hydraulic conductivity of Area I. 
reported by Bianchi (2003), the soil studied can be classified as very permeable; however, considering data in saturated areas at $10 \mathrm{~cm}$ of depth, this soil can be placed among very permeable, permeable and mediately permeable ones with a fine sand texture (Tables 9 and 10).

\section{The hydraulic flow in porous medium or soil perme- ability}

The $Q(\mathrm{Kfs})$ values are in the average: $17.5 \mathrm{l} \mathrm{h}^{-1}$ in not-saturated field at $5 \mathrm{~cm}$ of depth, and of $7.5 \mathrm{l} \mathrm{h}^{-1}$ in saturated field; $\mathrm{Q}$ (Vmean) values are in the average: $24 \mathrm{l} \mathrm{h}^{-1}$ in not-saturated field at $5 \mathrm{~cm}$ of depth, and of $8.2 \mathrm{l} \mathrm{h}^{-1}$ in saturated field and $Q(R)$ values are in the average: $20.8 \mathrm{l}$ $\mathrm{h}^{-1}$ in not-saturated field at $5 \mathrm{~cm}$ of depth, and of $7.9 \mathrm{l} \mathrm{h}^{-1}$ in saturated field (Table 9).

The intensity rain in sprinkler irrigation considering different systems (Bertolacci, 2008) changes from $3 \mathrm{~mm} \mathrm{~h}^{-1}$ to $20 \mathrm{~mm} \mathrm{~h}^{-1}$ (rarely reaching $80 \mathrm{~L} / \mathrm{h})$.

In the field studied, the values of $\mathrm{Kfs}, \mathrm{K}($ Vmedia) and $\mathrm{K}(\mathrm{R})$ always exceeded $100 \mathrm{mmh}^{-1}$ of permeability (Table 9 ); furthermore, with the actual irrigation systems there are not limits for intensity rain. Areas

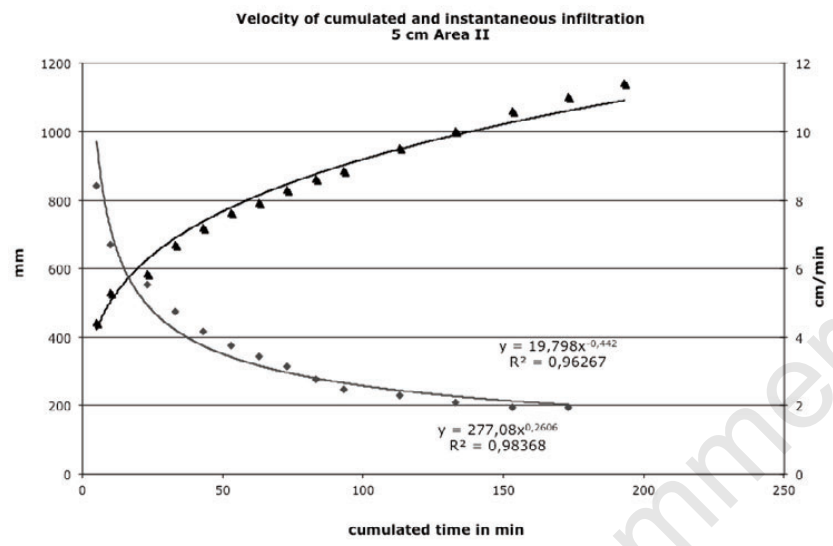

Figure 12. Cumulated and instantaneous hydraulic conductivity of Area II.

Field satured conductivity (Kfs) in $\mathrm{cm} \mathrm{s}^{-1 *} 10^{-4}$

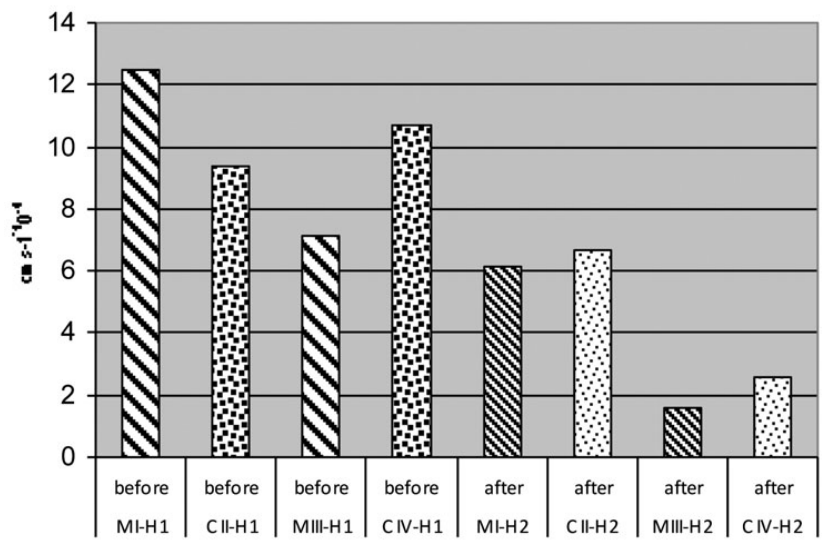

Figure 13. Saturated hydraulic conductivity or permeability Kfs.
III and IV showed lower values at $10 \mathrm{~cm}$ of depth (31 and $\left.56 \mathrm{mmh}^{-1}\right)$, exceeding the limit of $20 \mathrm{mmh}^{-1}$ of intensity rain (Tables 9 and 10).

Figure 17 shows the relation between the logarithm of infiltration intensity at the saturation point ( $\log \mathrm{Ks}$ ) and the hydraulic flow $\mathrm{Q}(\mathrm{K})$ of water typical of the examined soil.

The value of the coefficient of permeability at constant permeability (Ks), calculated by kfs is equivalent to that obtained by formulae given at the course on hydrogeology $\mathrm{K}(\mathrm{V}$ mean) and $\mathrm{K}(\mathrm{R})$, even if the latter gives lower values of soil permeability. Therefore, the curve of water flow obtained by $K(R)$ is lower compared with the other, but the present study suggests that it could be more convenient considering the lower value, which avoids the risk of an over-evaluation of water flow and of speed of infiltration at the saturation point.

\section{Conclusions}

The effect of the organic amendment, used only one time, is present in all parameters, even if with a low statistical significance $(\mathrm{P}<1-5 \%)$.

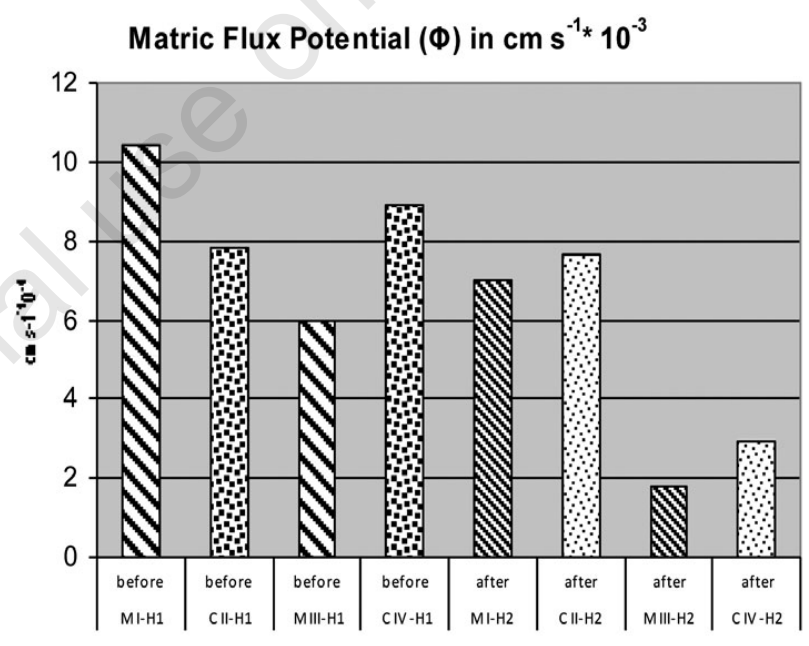

Figure 14. The matric flux potential $(\Phi)$.

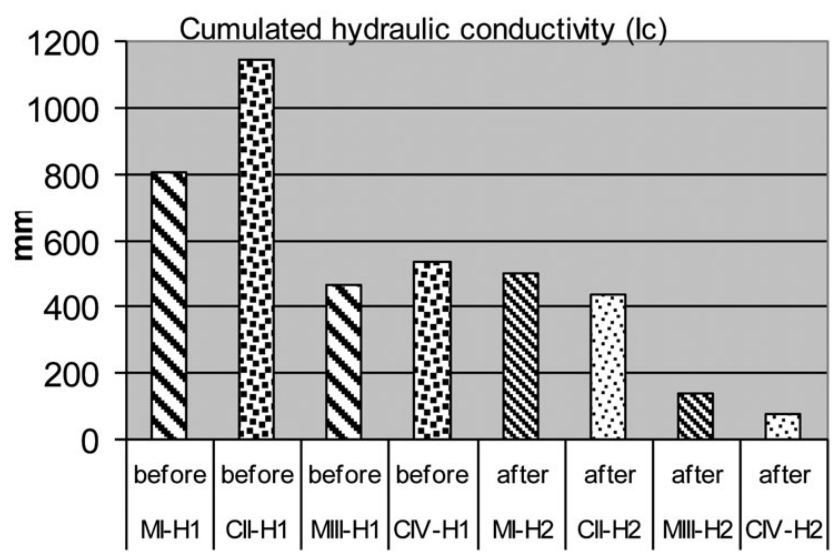

Figure 15. Cumulated hydraulic conductivity (Ic) in $\mathrm{mm}$. 
Table 9. Flow rate and hydraulic conductivity values found in the experimental station of Scafati (SA, Italy).

\begin{tabular}{|c|c|c|c|c|c|c|}
\hline Treatments & $\begin{array}{c}\mathrm{Kfs} \\
\mathrm{mm} \mathrm{h}^{-1}\end{array}$ & $\begin{array}{c}\mathrm{K}(\text { Vmean }) \\
\mathrm{mm} \mathrm{h}^{-1}\end{array}$ & $\begin{array}{c}\mathrm{K}(\mathrm{R}) \\
\mathrm{mm} \mathrm{h^{-1 }}\end{array}$ & $\begin{array}{r}Q(\mathrm{Kfs}) \\
\mathrm{L} \mathrm{h}^{-1}\end{array}$ & $\begin{array}{c}\text { Q(K (Vmean) } \\
\mathrm{L} \mathrm{h}^{-1}\end{array}$ & $\begin{array}{l}Q(R) \\
L h^{-1}\end{array}$ \\
\hline MI- $\mathrm{H}_{1}$ & 312.05 & 393.60 & 241.92 & 22.06 & 27.82 & 26.14 \\
\hline CII- $\mathrm{H}_{1}$ & 235.11 & 481.92 & 183.17 & 16.62 & 34.06 & 19.79 \\
\hline MIII- $\mathrm{H}_{1}$ & 178.47 & 218.88 & 138.24 & 12.62 & 15.47 & 14.94 \\
\hline CIV-H & 267.17 & 264.00 & 207.36 & 18.89 & 18.66 & 22.41 \\
\hline Mean M & 245.26 & 306.24 & 190.08 & 17.34 & 21.65 & 20.54 \\
\hline Mean C & 251.14 & 372.96 & 195.26 & 17.75 & 26.36 & 21.10 \\
\hline Mean & 248.20 & 339.60 & 192.67 & 17.54 & 24.00 & 20.82 \\
\hline MI- $\mathrm{H}_{2}$ & 152.76 & 181.74 & 131.98 & 10.80 & 12.85 & 14.26 \\
\hline CII- $\mathrm{H}_{2}$ & 167.57 & 166.92 & 132.54 & 11.84 & 11.80 & 14.32 \\
\hline MIII- $\mathrm{H}_{2}$ & 38.97 & 48.36 & 30.89 & 2.75 & 3.42 & 3.34 \\
\hline CIV-H${ }_{2}$ & 64.69 & 67.86 & 56.16 & 4.57 & 4.80 & 6.07 \\
\hline Mean M & 95.86 & 115.05 & 81.43 & 6.78 & 8.13 & 8.80 \\
\hline Mean C & 116.13 & 117.39 & 94.35 & 8.21 & 8.30 & 10.20 \\
\hline Mean & 106.00 & 116.22 & 87.89 & 7.49 & 8.22 & 9.50 \\
\hline
\end{tabular}

Table 10. Reported by Bianchi, 2003.

\begin{tabular}{|c|c|c|c|}
\hline Type of soil & $\begin{array}{c}\mathrm{K} \\
\mathrm{mm} \mathrm{h}^{-1}\end{array}$ & $\begin{array}{c}\mathrm{cm} \\
\sec ^{-1}\end{array}$ & $\begin{array}{c}\text { Granulometric } \\
\text { categories }\end{array}$ \\
\hline Very permeable & $>150$ & $>0.0042$ & Fine sand \\
\hline Permeable & $50 \div 150$ & $0.0014 \div 0.0042$ & Fine sand \\
\hline Middle permeable & $15 \div 50$ & $0.0004 \div 0.0042$ & $\begin{array}{l}\text { Loamy sand+ } \\
\text { fine sand }\end{array}$ \\
\hline Moderately permeable & $5 \div 15$ & $0.0001 \div 0.0004$ & Loamy sand \\
\hline Few permeable & $1.5 \div 5$ & $0.00004 \div 0.0001$ & $\begin{array}{l}\text { Loam+loamy } \\
\text { sand }\end{array}$ \\
\hline Very few permeable & $<1.5$ & $<0.00004$ & Loam \\
\hline
\end{tabular}

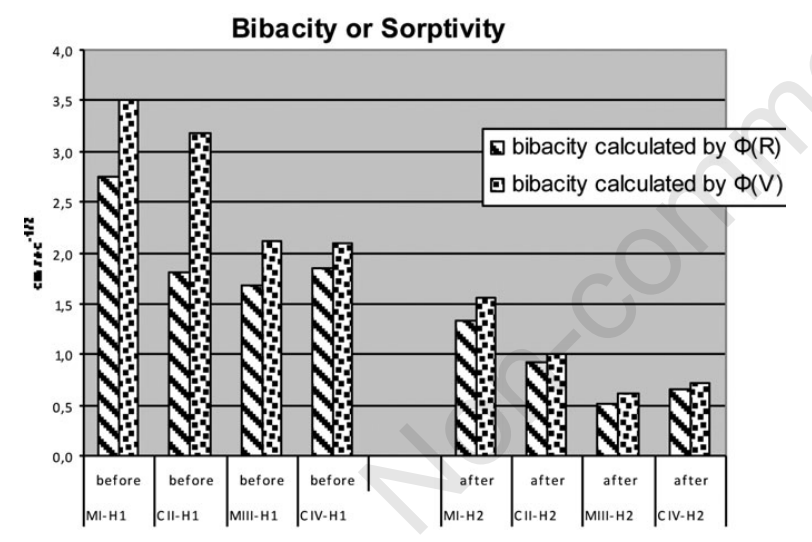

Figure 16. Bibacity (B) or sorptivity (S).

Relation between the $\log$ of $k$ and $Q$

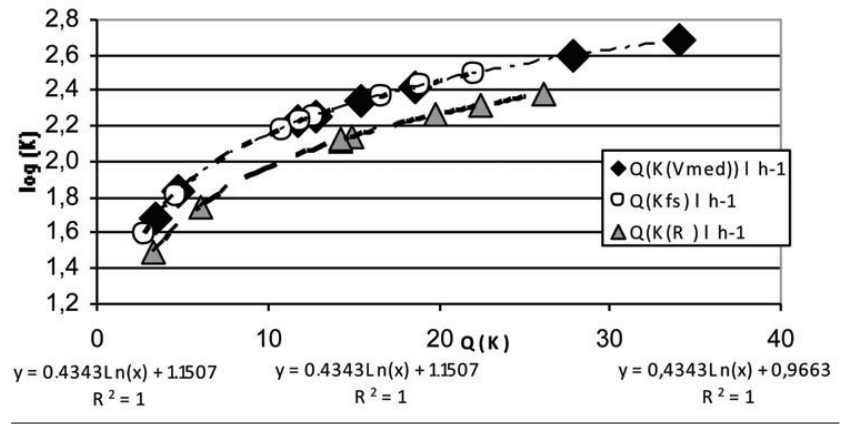

Figure 17. Relation between the hydraulic flow $(Q)$ and log of saturated hydraulic conductivity (Ks).
This biomass stores a better water reserve and causes a lower avidity for water (bibacity) and a better speed of percolation of exceeding water, with considerable advantage for the plants. The results showed that the field was divided in two parts, having lower values in one part compared with the other one; for this reason it is relevant to examine the variation of saturated hydraulic conductivity along field.The organic matter used in the past, before this experience, decreased the variability of soil. In conclusion, the soil analysed showed to be almost permeable and did not have big problems in intensity rain of currently used sprinkler irrigation systems, even if it was present a large variation in field.

\section{References}

Basile A., Terribile F., 2008. La ricerca sull'inquinamento da nitrati nei suoli campani: un approccio modellistico nella gestione agro-ambientali. Monografia Regione Campania Ed., Napoli, Italy.

Bianchi A., 2003. Bonifica e drenaggio del terreno. Available from: http://.www.cremona. polimi.it/msa/get_img.ph

Bertolacci M. 2008. Prestazioni funzionali di alcune attrezzature per l'erogazione irrigua impiegate nel florovivaismo. Available from: http://www.lni.unipi.it/pubblicazioni.htm.

Cavazza L., Torri D., 1997. Proprietà idrologiche del suolo. In: M. Pagliai and F. Angeli (eds.) Metodi di Analisi fisica del suolo. MiPAF Ed., Roma, Italy, Chap. VIII, pp 109-115.

Erlick D.E., Reynolds W.D., Tan K.A., 1989. Hydraulic conductivity measurements in the unsaturated zone using improved well analyses. Ground Water Monit. Rev. 9:184-193.

Fares A., Abbas F., Ahmad A., Deenik J.L., Safeeq M., 2008. Response of selected Soil Physical and Hydrologic Properties To Manure Amendments Rates Levels, Anditypes. Soil Science 173:552-533.

Falciai M., 1993. Tecnica dell'irrigazione. Available from: http://www.deistaf.unifi.it/upload/sub/ personale/falciai/tecnicairrigazione.pdf

FA0, 1998. World Reference Base for Soil Resources. Report No 84. Available from: http://www.fao.org/nr/land/soils/soil/wrb-documents/en/

Franzluebbers A.J., 2002. Water Infiltration and soil structure related to organic matter and its stratification with depth. Soil Till. Res. 66:197-205.

Fileccia A., 2002-2009. Course of Applied Hydrology. Department of Geological, Environmental and Marine Sciences, University of 
Trieste, Italy. Available from: http://www.filecciageologia.it/

Grant S.A., 2004. Hydraulic properties, temperature effect. In: D. Hillel (ed.) Encyclopedia of Soils in the Environment. Elsevier Inc. Publ., Philadelphia, PA, USA, pp 207-211.

Leeds Harrison P.B., Yongs E.G., 1997. Estimating hydraulic conductivity of aggregates conditioned by different tillage treatments from sorption measurements. Soil Till. Res. 31:141-147.

Marsili A., Servadio P., Pagliai M., Vignozzi N. 1998. Changes of some physical properties of a clay soil following the passage of rubberand metal-tracked tractors. Soil Till. Res. 49:185-199.

Matula S., 2003. The influence of tillage treatments on water infiltration into soil profile. Plant Soil Environ 49:298-306.

Megale P.G., 2009. Quaderni di Idraulica Agraria. Richiami di Idrologia dell'Irrigazione. Università di Pisa, Italy. Available from: http:/www.Ini.unipi.it/dispense.htm

Mubarak I., Maihol J.C., Angulo-Jaramillo R., Ruelle P., Boivin P., Khaledian M., 2009. Temporal Variability in soil hydraulic properties under drip irrigation. Ed Geoderma 150:158-165.

Nigrella G., 1994. Guelf permeameter and the Kfs. Available from: http:/www.naturaweb.net/ pdf/permeametro.pdf

Pagliai M., Marca M.LA., Lucamante G. 1987. Changes in Soil Porosity in Remolded Soils Treated With Poultry Manure. Soil Sci. 144:128140.

Pagliai M., Marsili A., Servadio P., Vignozzi N., Pellegrini S., 2003. Changes of some physical properties of a clay soil following the passage of rubber tracked and wheeled tractors of medium power. Soil Till. Res. 73:199-129.
Reynolds WD., 1993. Saturated hydraulic conductivity: field measurement. In: M.R. Carter and Canadian Society of Soil Science (eds.) Soil Sampling and Methods of Analysis, 3rd ed. Lewis Publ., Boca Raton, FL, USA.

Sartori G., Ferrari G.A., Pagliai M., 1985. Changes in soil porosity and surface shrinkage in a remolded, saline clay soil treated with compost. Soil Sci. 139:523-530.

Servadio P., Marsili A., Pagliai M., Pellegrini S., Vignozzi N., 2001. Effects on some clay soil qualities following the passage of the rubber-tracked and wheeled tractors in central Italy. Soil Till. Res. 61:143-155.

Servadio P., Marsili A., Vignozzi N., Pellegrini S., Pagliai M., 2005. Effects on some soil qualities in central Italy following the passage of four wheel drive tractorfitted with single and dual tires. Soil Till. Res. 84:87-100.

Soilmoisture Equipment Corp., 2008. Guelph Permeameter 2800K1 Operating Instructions. Santa Barbara, CA, USA. Available from: http://www.soilmoisture.com/pdf/2800k1.pdf

USACE, 1999. Groundwater hydrology. Engineer Manual 1110-2-1421. U.S. Army Corps of Engineers. Washington, DC, USA. Available from: http://140.194.76.129/publications/ eng-manuals/em1110-21421/entire.pdf

Various Authors, 2005-2006. Course of Hydrology. Lessons IV-V, Second University of Naples (SUN), Department of Civil Engineer. Available from: http://www.dic.unina2.it/index.php ?sezione=persone\&id=robgreco\&azione $=$ didattica\&mostra $=1$ 